Finally, we feel confident that the positive result of the Maugeri Foundation Respiratory Failure item set (MRF-28) questionnaire [3] assessment in the treated subjects, also showed a positive impact of one of the most important endpoints of the long-term ventilatory strategy in these patients, which is the health-related quality of life (HRQoL). Although, it is still not clear whether survival can be positively influenced by NPPV in addition to standard long-term oxygen therapy (LTOT), the result obtained on specific HRQoL (together with the positive, although not significant, trend towards the reduction in the follow-up admissions in the critical care area) seems to justify the prescripton of NPPV, at least when a poor condition of the patient (i.e. severe disability, frequent exacerbations and hospitalisations, low effect and clinical control by LTOT) can be proven.

Obviously, any conclusion should be made with caution at present. However, although the prescription of noninvasive positive pressure ventilation cannot be recommended as a generalised option in the chronic obstructive pulmonary disease patients, an effort should be made to look for the best candidates on the basis of their history and the pathophysiological background available.
E. Clini*, N. Ambrosino

*Division of Pulmonary Rehabilitation, Fondazione Villa Pineta ONLUS, Pavullo and ${ }^{\#}$ Cardiosurgery Dept, Division of Pneumology, Azienda Ospedaliera Pisana, Pisa, Italy.

\section{References}

1. Clini E, Sturani C, Rossi A, et al. on behalf of the Rehabilitation and Chronic Care Study Group, Italian Association of Hospital Pulmonologisis (AIPO). The Italian mulitcentre study on noninvasive ventilation in chronic obstructive pulmonary disease patients. Eur Respir $J$ 2002; 20: $529-538$.

2. Meecham Jones DJ, Paul EA, Jones PW, Wedzicha JA. Nasal pressure support ventilation plus oxygen compared with oxygen therapy alone in hypercapnic COPD. $\mathrm{Am}$ J Respir Crit Care Med 1995; 152: 538-544, 1327.

3. Carone M, Bertolotti G, Anchisi F, et al. Analysis of factors that characterize health impairment in patients with chronic respiratory failure. Eur Respir J 1999; 13: 1293-1300.

\title{
Survival in COPD patients after regular use of fluticasone propionate and salmeterol
}

\section{To the Editor:}

I read with interest the paper by SORIANO et al. [1], in which the authors stated that fluticasone proprionate alone or in combination with salmeterol is associated with increased survival of chronic obstructive pulmonary disease (COPD) patients managed in primary care.

First, according to their data, the authors should have considered replacing fluticasone with inhaled steroids. More importantly, they did not discuss potential limitations that could have cast doubt on this statement.

Some of the data presented in table 1 of this paper pointed towards potential important differences between the three "active" groups and the reference group at baseline. Indeed, baseline treatment in the three groups receiving fluticasone and/or salmeterol could be described as fairly typical for moderate-to-severe COPD patients, with $>90 \%$ of the patients receiving inhaled bronchodilators. In contrast, less than onehalf of the reference group used inhaled bronchodilators at baseline, which is also clearly different from the reality of drug use in COPD in the UK [2]. This is peculiar for a group of COPD patients that show a high mortality. The $25 \%$ mortality at $2 \mathrm{yrs}$ in this group parallels the prognosis of COPD patients requiring long-term oxygen therapy [3, 4] or with a forced expiratory volume in one second (FEV1) of $<30 \%$ predicted in the intermittent positive pressure breathing trial [5].

Moreover, patients in the reference group were significantly older, had significantly more comorbidities (the combination of the two pointing towards potentially more severe comorbidities), and were less likely to have severe COPD as defined by the authors (use of oxygen or nebulised therapy).

Finally, the cause of death was not reported.

These points lead to the following questions being raised. 1) Could the method of inclusion in the UK General Practice Research Database (GPRD) explain these differences? Neither the description by the authors nor previous papers related to the GPRD [6-8] clarify whether inclusion in the database as a COPD patient required contact with a general practitioner (GP) for primary diagnosis of COPD or whether the mention of COPD at a contact for another purpose (and therefore as a secondary diagnosis) was sufficient. Since COPD is prevalent, particularly so in an old population such as the reference group of SORIANO et al. [1] (mean age \pm SD $72 \pm 10 \mathrm{yrs}$ ) [9], the detection of COPD as a secondary diagnosis when contact is made with the GP should not be a rare occurrence. Accordingly, the primary reason for the healthcare contact leading to the inclusion in the GPRD could have been a comorbid state with a worse prognosis. This could play a role in the higher all-cause mortality observed in the reference group. 2) The authors reported the sensitivity of a diagnosis of COPD in the GPRD but did not report the specificity, which is equally important in the interpretation of their data. As patients from the three active groups seem to be quite typical COPD populations, could patients misdiagnosed as COPD be overrepresented in the reference group? 3) Since other studies based on the GPRD were related to the cause of death recorded in the database [10,11], could the authors have clarified whether the cause of death was available in the different groups?

\section{E. Marchand}

Service de Pneumologie, Cliniques Universitaires UCL de Mont-Godinne, B-5530 Yvoir, Belgium.

\section{References}

1. Soriano JB, Vestbo J, Pride NB, Kiri V, Maden C, Maier WC. Survival in COPD patients after regular use of fluticasone propionate and salmeterol in general practice. Eur Respir J 2002; 20: 819-825. 
2. Rudolf M. The reality of drug use in COPD: the European perspective. Chest 2000; 117: 29S-32S.

3. Nocturnal Oxygen Therapy Trial Group. Continuous or nocturnal oxygen therapy in hypoxemic chronic obstructive lung disease. A clinical trial. Ann Intern Med 1980; 93: 391-398.

4. Hjalmarsen A, Melbye H, Wilsgaard T, Holmboe JH, Opdahl R, Viitanen M. Prognosis for chronic obstructive pulmonary disease patients who receive long-term oxygen therapy. Int J Tuberc Lung Dis 1999; 3: 1120-1126.

5. Anthonisen NR, Wright EC, Hodgkin JE. Prognosis in chronic obstructive pulmonary disease. Am Rev Respir Dis 1986; 133: 14-20.

6. Hansell A, Hollowell J, Nichols T, McNiece R, Strachan D. Use of the General Practice Research Database (GPRD) for respiratory epidemiology: a comparison with the 4th Morbidity Survey in General Practice (MSGP4). Thorax 1999; 54: 413-419.

7. Soriano JB, Maier WC, Egger P, et al. Recent trends in physician diagnosed COPD in women and men in the UK. Thorax 2000; 55: 789-794.

8. Lawson DH, Sherman V, Hollowell J. The General Practice Research Database. Scientific and Ethical Advisory Group. QJM 1998; 91: 445-452.

9. Mannino DM, Gagnon RC, Petty TL, Lydick E. Obstructive lung disease and low lung function in adults in the United States: data from the national health and nutrition examination survey, 1988-1994. Arch Intern Med 2000; 160: $1683-1689$.

10. Jick H, Jick SS, Gurewich V, Myers MW, Vasilakis C. Risk of idiopathic cardiovascular death and nonfatal venous thromboembolism in women using oral contraceptives with differing progestagen components. Lancet 1995; 346: 1589-1593.

11. Derby LE, Tennis P, Jick H. Sudden unexplained death among subjects with refractory epilepsy. Epilepsia 1996; 37: 931-935.

\section{From the authors:}

We thank E. Marchand for his interest and constructive comments relating to our paper [1] and we will try to answer his queries. Our findings for inhaled corticosteroids are likely to be a class effect. Our initial approach to the General Practice Research Database (GPRD) was done in order to mimic a planned controlled trial and therefore fluticasone propionate was chosen. Our sensitivity analysis did not reveal different findings when all inhaled corticosteroids were included in the analyses as illustrated in figure 4 of the paper. We understand E. Marchand's concern about comparability between groups but disagree with his conclusions. Table 1 showed baseline characteristics, i.e. before the groups were defined according to their prescriptions, within a 6 -month period. This explains why less than one-half of the reference group seemed to be without inhaled bronchodilators; in the following 6-month period, all of them received at least three prescriptions for shortacting $\beta$-agonists, xanthines, anticholinergics or combined bronchodilators. Similarly, in the group receiving salmeterol in the 6-month period defining drug exposure, only $23.9 \%$ received long-acting $\beta$-agonists at baseline; for inhaled corticosteroids the figure was $67.3 \%$ at baseline. For this reason, all four groups received "active" treatment during the first 6 months and a well-sustained pattern of prescriptions throughout 3 yrs. However, this terminology should be used in clinical trials only, not in observational studies in pharmacoepidemiology [2]. E. Marchand is right in pointing out the difference in age but we have tried to adjust for these potential confounders using both multivariate survival analyses and stratification on age. It is true that use of nebulised therapy was less frequent in the reference group but oxygen therapy did not, in fact, differ.

Thus, in response to E. Marchand's specific questions, we would make the following comments. 1) Based on the above, we doubt that recording and misclassification in the GPRD explain our findings. The exact circumstances at which a label of chronic obstructive pulmonary disease (COPD) is entered into the register cannot be seen from the register data but it is fair to hypothesise that the first labelling of COPD in a primary care database could serve as a proxy for incidence of clinical COPD. Since all patients were entered because of prescriptions for COPD drugs, as recommended by the current British Thoracic Society (BTS) and Global Initiative for Chronic Obstructive Lung Disease (GOLD) guidelines [3, 4], we believe we have overcome the potential bias suggested by E. Marchand. 2) The specificity of our definitions of moderate and severe COPD were $75.0 \%$ and $81.4 \%$, respectively [5]. 3) We consider overall mortality a much more exact end-point than cause-specific mortality, especially since studies on causes and circumstances of death in COPD are generally difficult to perform $[6,7]$. We visually reviewed all information on the 1,334 deaths observed in this cohort. Without any validation study to lean on we can say that causes of death were respiratory in $33.8 \%$, cardiovascular in $24.4 \%$, cancer in $16.1 \%$, other in $8.5 \%$, and unknown in $17.2 \%$. There was no difference in the pattern of causes of death in the four groups, but it was beyond our protocol to expect that any respiratory medication would reduce specific causes of death.

\section{J.B. Soriano*,\#, J. Vestbo ${ }^{\uparrow}$, N.B. Pride ${ }^{+}$}

*Worldwide Epidemiology, GlaxoSmithKline Research and Development, Greenford, ${ }^{\text {\#} H e a l t h ~ P r o m o t i o n ~ R e s e a r c h ~ U n i t, ~}$ London School of Hygiene and Tropical Medicine and ${ }^{+}$Thoracic Medicine, National Heart and Lung Institute, Imperial College School of Medicine, London, UK. "Dept of Respiratory Medicine, Hvidovre University Hospital, Hvidovre, Denmark.

\section{References}

1. Soriano JB, Vestbo J, Pride NB, Kiri V, Maden C, Maier WC. Survival in COPD patients after regular use of fluticasone propionate and salmeterol in general practice. Eur Respir $J$ 2002; 20: 819-825.

2. Strom BL. Pharmacoepidemiology. 3rd Edn. Chichester, John Wiley \& Sons, 2000.

3. The COPD Guidelines Group of the Standards of Care Committee of the BTS. BTS guidelines for the management of chronic obstructive pulmonary disease. Thorax 1997; 52: Suppl. 5, S1-S28.

4. Pauwels RA, Buist AS, Calverley PM, et al. Global strategy for the diagnosis, management, and prevention of chronic obstructive pulmonary disease. NHLBI/WHO Global Initiative for Chronic Obstructive Lung Disease (GOLD) workshop summary. Am J Respir Crit Care Med 2001; 163: 1256-1276.

5. Soriano JB, Maier WC, Kiri V, Pride NB. Validation of general practitioner-diagnosed COPD in the UK General Practice Research Database. Eur J Epidemiol 2003 (in press).

6. Zielinski J, MacNee W, Wedzicha J, et al. Causes of death in patients with COPD and chronic respiratory failure. Monaldi Arch Chest Dis 1997; 52: 43-47.

7. Zielinski J. Circumstances of death in chronic obstructive pulmonary disease. Monaldi Arch Chest Dis 1998; 53: 324-330. 